\title{
Nominal-Time Analysis of Cotton Prices in China Impacts the Use of Granger Causality in Vector Error Correction Model
}

\author{
Eddy Hope Kabasele Bambe*, Ya-Bing Li
}

Institute of Cotton Research of Caas, China

\begin{tabular}{l} 
A R T I C L E I N F O \\
Research Article \\
Received 21 June 2017 \\
Accepted 26 September 2018 \\
\hline
\end{tabular}

Keywords:

Real cotton prices

Nominal cotton prices

Volatility in cotton prices

VECMs

Granger causality

Impulse response. \begin{abstract}
A B S T R A C T
The paper aims consists of modelling the cotton price index in China to determine the dependency of the previous increase in cotton prices on stocks and imports of cotton in the internal market during the sample period from 1991 to 2014. The paper opted for an empirical study using the time-series Vector Error Correction Model (VECM) framework. The paper provides empirical insights about the innovation of cotton price in domestic market of the China. It suggests that there are bidirectional relationships among the price and the stock in a system. It suggests also that cotton imports serve a significant role in the price index of current trends relative to future stocks. Thus, we concluded that the previous high cotton prices in China were attributed to the previous need to increase cotton stocks but not directly via the import of cotton; however, the latter may have a significant role in the future.
\end{abstract}

*Corresponding Author:

E-mail: eddiehope61@yahoo.fr

DOI: https://doi.org/10.24925/turjaf.v6i12.1690-1700.1385

\section{Introduction}

Recently, the time series analysis of cotton prices has captured significant attention. With recent cotton prices above historical averages in the domestic market of China, users of time series data analyse previous data to explain price concerns using econometric tools. Presently, China holds almost $50 \%$ of the global cotton stocks and is the largest importer of cotton; it has imported approximately 36 percent of the world's cotton imports since 2012 (International Cotton Advisory Committee, Government Support to the Cotton Industry, October 2012). Therefore, the price index and stock fluctuation of cotton lint has become one of the main variables in the model-based macroeconomic projections generated by the Chinese government and the World Trade Organization (WTO) (ICTSD, May 2013). During the commodity price boom (bulls) and bust (bears) of 2007-2008, cotton futures prices significantly increased and decreased despite the high levels of inventory (Joseph P. Janzen, 2012). For instance, the world has experienced two commodity price booms since 2006, in which the prices of many commodities significantly increased. Between 2006 and 2008, the price of cotton doubled, the price of wheat tripled, and the price of corn more than tripled. As these prices increased, commodity prices decreased in 2008 before a second boom commenced in 2009 and 2010 (Commodity Research Bureau, 2011). However, during this period, the sector industry of cotton in China exhibited a positive evolving trend for the price index. Conversely, the price index continued to increase during both of these periods of the boom and the bust. According to the ICAC Secretariat, in 2011/12, ten countries provided subsidies to their cotton industry. China was the largest provider of subsidies in 2011/12 (total subsidies, not equivalent to subsidy per pound of cotton). China has been the largest provider of support to its cotton sector since 2009/10 and has overtaken the United States. With a new minimum support price policy and import quotas, domestic cotton prices in China have been maintained well above international cotton prices. The total government support provided to the Chinese cotton sector was estimated to be USD 3 billion in 2011/12. China's current minimum support price policy has translated into purchases of more than nine million tons of cotton from domestic crops in 2011/12 and 2012/13 and more than one million tons of foreign cotton between October 2011 and March 2013. In comparison, the total support 
provided to the U.S. cotton sector was approximately USD 820 million via subsidized crop insurance (ICAC, October 2012). In 2012/13, the Chinese government's accumulation of cotton into a very large national reserve prevented a rapid accumulation of stocks by the remainder of the world and a rapid decline of international cotton prices. Since the price peak in 2010/2011, China became a significant supporter of cotton, with its support increasing more than fivefold between 2007/08 and 2012/13 by the ICAC measure, which merits specific examination. Support in the majority of other countries has either remained fixed or increased but not by several fold in the intervening period. During these times in the world market, the price of cotton continued to decrease. As suggested by Silvennoinen and Thorp (2010), commodity price changes, such as changes observed since 2006, may be strongly correlated due to fundamental supply and demand relationships. In their study, Joseph P. Janzen, Aaron D. Smith, and Colin A. Carter (2012) suggest that demand from inventory holders will affect current prices when the cost generated by holding inventory is considered. The empirical validity of the supply-ofstorage model was questioned in a series of papers by Deaton and Laroque (1992, 1996), who attempted to match predictions from the model to real-world data on commodity prices.

Recently, Cafiero et al. (2011) empirically confirmed the kinked demand curve for storable commodities, which indicates that the presence of high- and low-volatility periods in prices is associated with low and high levels of inventories. We also observed this similarity when we analysed the technical factors that affect the variation in cotton prices in recent decades in the domestic market of cotton in China. China's offers of cotton received the highest spot price due to the intervention of the policymaker to purchasing the cotton to maintain the level of stockpile of the national reserve. This constant demand-of-storage with high prices significantly contributed by protecting producers and suppliers of white gold. Another factor that affects the decline in the price of commodities in the world market is the notion that commodities may be substitutes or complements in production or consumption. Tisdell and McDonald (1979) stressed that the prime reason for cotton's reduced share of the textile fiber market is increased competition from man-made fibers. Similar comparisons were made by UNEP (2002) shortly after China joined the World Trade Organization (WTO). In 2001, the inclusion of China in the WTO was considered to be an opportunity and challenge by Chinese producers. The uneasiness felt by producers was measured by 'UNEP' in his study of the impact of trade liberalization from China in the cotton sector. The results of the analysis indicated that liberalization of the cotton trade in China has negative impacts on the social life of the producers and the environment. Consequently, the Chinese government has adopted the previously outlined strategies with consequent highly volatile prices of cotton due to an increase in stocks.

Therefore, this concurrence and irrational price behaviours pose problems for people who rely on these markets for reliable price discovery and people who use these markets to hedge price risk. Thus, traders who are active in commodity markets understand and expect correlation or comovement based on the previously described. However, the relationship between the price differential for delivery at different dates and the level of inventories is acknowledged as a stylized fact in storable commodity markets (Carter and Revoredo-Giha, 2007). Alice Shiu (2004) evaluated the electricity consumption and economic growth in China using an error-correction model to examine the causal relationship between electricity consumption and the real GDP for China from 1971-2000. Joseph P. Janzen, Aaron D. Smith, and Colin A (2012) also studied this relationship in Carter Commodity Price Comovement: the Case of Cotton. These authors demonstrated the VECM as an important measurement tool in macroeconomics for estimating the policy implemented by the policymaker and to acquire new insight into the formulation of new policies. We develop a VECM environment framework to analyse the domestic market of cotton of China from 1991 to 2014 and employ a data generating process (DGP) to determine the existence of a causal relationship among the random variables. The study is vital in policy formulation and implementation in the sector industry of cotton in China since it entered a new "transition phase" in 2014. The purpose of this paper is to analyse the relationships among the cotton price index, stocks of cotton, and imports of cotton in the domestic market of China to econometrically verify the causality relationships among the selected random variables. Our motivation for this study is justified by the lack of studies about the causal relationships among the factors that affect the internal market of cotton in China. The available data for this study was limited. The scheme of this study is as follows: Section 2 provides the statistical description and pattern shape of the time series; Section 3 outlines the literature methodology and the dataset of the time series; Section 4 presents the empirical findings; Section 5 offers some concluding remarks and highlights the policy implications of our outcome.

\section{Time Series Patterns and Stationarity of Variables}

A time series is a sequence of observations for a variable that is measured at successive points in time or over successive periods of time. The objective of time series analysis is to discover a pattern in the historical data or time series and extrapolate the pattern into the future. The pattern of the data is an important factor in understanding how the time series has behaved in the past. If this behaviour is expected to continue in the future, we can employ the past pattern to guide the selection of an appropriate forecasting method. To analyse the variables, we have plotted a frame that contains the three linear charts of the time series for the variables. The goal is to identify the underlying pattern in the data; a useful first step is to construct a time series plot, which depicts the relationship between the time variable and the time series variable. Time is represented on the horizontal axis, and the time series values are shown on the vertical axis. By plotting the figure, we search for the possible existence of common types of data patterns that can be identified from a time series plot. 
$P$

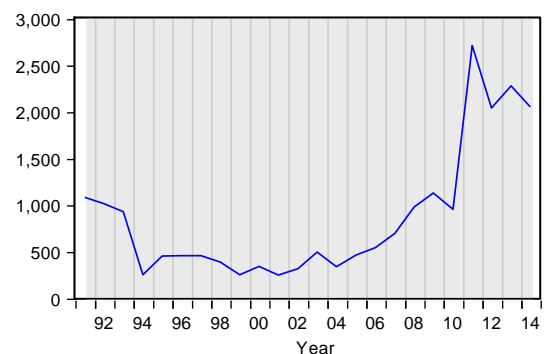

STC

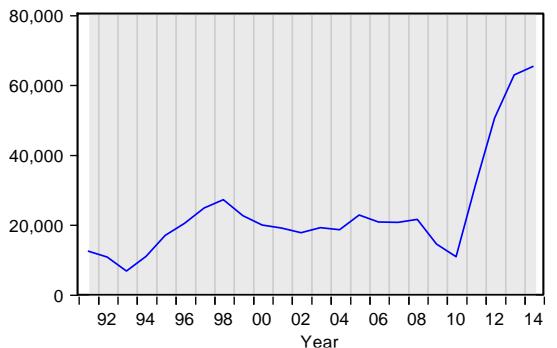

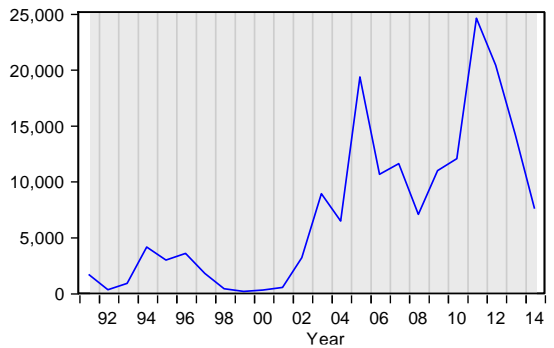

Figure 1 The trend of the price of cotton (P), the stock of cotton (STC), and the import of cotton (I) over the past 24 years (We had deflated the nominal cotton prices index on a base year 1990=100 with data of exchange rate coming to the World Bank. it is worth noting, however, that the real cotton prices were only used for graphical proposal)

The Figure 1 shows the trend of the price of cotton (P), the stock of cotton (STC), and the import of cotton (I) over the past 24 years. The average value per year for these three time series variables are 866.13 US dollar per ton, $23477.171000480 \mathrm{Ib}$. Bales, and 7170.7501000480 Ib. Bales, respectively. Although random variability is present, these data follow a horizontal pattern. Descriptively, the distribution of data is not Gaussian over time, with the exception of the import of cotton, for which the data were normally distributed. The value of kurtosis is approximately 2.9, which is platykurtic; thus, comovement into the series is occurs over time. However, we identified the leptokurtic in the real-valued random variables of the time series; for instance, from the cotton price index and stock with the highest probabilities of order of approximately 4.9 and 5.2, respectively. These were greater than 3 for the threshold kurtosis hat is required for a normal distribution, which indicates that the probability mass is concentrated in the tails of the distribution rather than around the mean of the distribution, i.e., by forming a cluster kurtosis in the distribution in the series over time. The skewness was greater than 0 (zero) for the cotton price and stock of the order of 1.5 and 17, respectively, which indicates that the tail on the right side of the distribution of both series is longer or larger than the left side of the distribution; thus, a unimodal asymmetry is apparent. The skewness of import 0.9 was drawn slightly close to 1 , which indicates that the tails on both sides were slightly in a mean balance; thus, the distribution was almost unimodal symmetric over time. We consider how we can remove the trend in the time series to determine, for instance, if the series became stationary. Changes in business conditions due to the intervention of policy makers frequently produces a time series that has a horizontal pattern of shifting to a new level. For instance, at the end of 2013/2014, the Chinese government decided to reduce support to producers to satisfy the demand for cotton. Consequently, we have observed a decrease in the evolving negative trend of cotton prices of approximately $21.76 \%$ compared with the trend for $2013 / 2014$. With this new policy, policy makers expect a significant increase in the yearly demand of the consumption of cotton beginning this year.

We understand that the original horizontal pattern the chart of the cotton prices, demand, and cotton supply will shift up or down. Note the expected decrease in the level of cotton prices in the time series beginning in 2015, i.e., this change in the level of the time series in the current year hinders the establishment of a suitable framework to select an appropriate forecasting method in the future. The selection of a forecasting method that adapts to changes in the level of a time series is an important consideration in many practical applications, especially in business in the agriculture sector, in which risk and uncertainty are significant. Although time series data of random fluctuations usually show a series of timing, they may also show changes or progressive movements with relatively higher or lower values over a longer period of time. If a time series plot shows this type of behavior, a trend pattern exists. In the figure, almost all of the time series variables exhibit a trend pattern movement in their behavior, which is generally a shift or a movement, whose feature is exponential fashion. Note that one ton of raw cotton was sold at approximately 246.60 US dollar in 2001, and 311.62 US dollar was sold in 2002. Ten years later, i.e., in 2011, one ton of raw cotton was sold at approximately 2707.39 US dollar, which demonstrates inflation of more than $997.88 \%$. A visual inspection of the plot of the time series exhibits some upward and downward movement over the past 20 years, and the series of time also seems to have a tendency to systematically increase or move in an upward direction. The trend of a time series can be identified by analyzing multiyear movements in historical data. In this figure, a cyclical pattern exists because the time series of each chart shows an alternating sequence of points below and above the trend line, which continues for more than one year. The cyclical component of a time series is frequently attributed to multiyear business cycles. For example, periods of moderate inflation followed by periods of rapid inflation can produce time series that alternate below and above a generally increasing trend line (e.g., a time series for housing costs). Business cycles are extremely difficult, if not impossible, to forecast. As a result, cyclical effects are often combined with long-term trend effects and are referred to as trend-cycle effects. In this section, we do not address cyclical effects in the time series. However, a cyclical pattern is observed in some time series variables, which indicates that the data of variables in this study are nonstationary. We are restricted by this aspect of time series patterns and the stationarity of variables to explain how we can transform our nonstationary variables into stationary variables. 


\section{Methodology in VECM and Dataset}

Regarding the methodology of this study, we combine our scientific approaches throughout the study, from the design of the model until the expected result. First, we need to determine the lag criterion, such as information criteria for the SIC and the HQIC, the AIC, and the FPE due to its relevance in the test, for instance, the JohansenJuselius cointegration, the vector error correction model (VECMs), and the impulse response.

\section{Unit Root Test of Stationarity}

Generally, the data of the time series are nonstationary. To convert it to a stationary time series, differencing into series is necessary using differencing operations to produce other sets of observations, such as the first-differenced values and the second-differenced values. In the case in which a series is stationary without any differencing, it is designated as I (0) or integrated of order 0 . A series that has stationary first differences is designated as I (1) or integrated of order one (1). Several methods exist to test stationarity of the time series variables. Methods have been proposed by Dickey, D. and W. Fuller, 1979 (refer to equation (1)) and Phillips, P.C. and P. Perron, 1988 (refer to equation (2)).

The ADF test is based on estimating the test regression:

$$
Y_{t}=\beta_{0} D_{t}+\varphi Y_{t-1}+X_{p j=1} \psi_{j} \Delta y_{t-j}+\epsilon_{t}
$$

Where $D_{t}$ is a vector of deterministic terms (constant and trend) and the $\mathrm{p}$ lagged difference terms, $\Delta \mathrm{y}_{\mathrm{t}-\mathrm{j}}$ are used to approximate the ARMA structure of the errors, and the value of $p$ is set to ensure that the error $\varepsilon_{t}$ is serially uncorrelated. The error term is also assumed to be homoscedastic. The specification of the deterministic terms is dependent on the assumed behaviour of $y_{t}$ under the alternative hypothesis of trend stationarity, as described in the previous section. Under the null hypothesis, $\mathrm{y}_{\mathrm{t}}$ is $\mathrm{I}(1)$, which implies that $\varphi=1$

The test regression for the Phillips, P.C. and P. Perron (PP) can be summarized as:

$$
\Delta \mathrm{Y}_{\mathrm{t}}=\beta_{0} \mathrm{D}_{\mathrm{t}}+\pi \mathrm{Y}_{\mathrm{t}-1}+\mathrm{u}_{\mathrm{t}}
$$

Where $u_{t}$ is $I(0)$ and may be heteroskedastic. The PP tests correct for any serial correlation and heteroskedasticity in the errors $\mathrm{u}_{\mathrm{t}}$ of the test regression by directly modifying the test statistics $t \pi=0$ and $T{ }^{\wedge} \pi$. As previously mentioned, our data showed the behaviors of the trend. Therefore, the trend properties of the data under the alternative hypothesis will determine the form of the test regression. The type of the deterministic terms in the test regression will influence the asymptotic distributions of the unit root test statistics. Consequently, our desire to extract the existence of a unit root in the variables prohibits transformation of the variables as far as possible in the first $\mathrm{I}(1)$, second $\mathrm{I}(2)$ or third difference, because we do not know the inherent behaviour of the original data.

\section{Model Selection Criteria}

Prior to fitting VECMs to estimate the time series $Y_{t}$, we applied a statistical model selection criteria. The idea is to fit all VEC models with an unknown lag selection criterion. We shall give significant importance to the lag selection criterion AIC because it is a model criteria selection that excels to parsimony, which minimizes some model selection criteria relative to other information criteria, such as SIC, the HQIC, and the FPE. The expected lag distance of VEC models can be estimated in the cotton price index using the Akaike information criterion (AIC) (Akaike 1974)

$$
\mathrm{AIC}=-2 \log \mathrm{L}+2 \mathrm{~K}
$$

Where $\log \mathrm{L}$ is the maximized $\log$-likelihood and $\mathrm{K}$ is the parameter richness of the model. As the parameter richness is increased, $\log \mathrm{L}$ is expected to decrease as the 'penalty term' increases; thus, the model with the lowest AIC will be a balance between parameter richness and the informativeness of additional parameters. Because our sample size is small, we seek to make a reasoned choice of number of lag selection that accurately corresponds to the sample size and of the model. Generally, because we have the yearly data, the maximum lag length may be one or two.

\section{Vector Error Correction Model (VECM) and Impulse}

\section{Response}

Because Johansen suggests that an existence of cointegrating relationships among the endogenous variables, which indicates that the random variables of the system can move together in short- or long -term equilibrium, we can apply a VEC model environment. VEC estimates the parameters via maximum likelihood estimate (MLE); we assume that we will use it with one rank number of cointegrating (1), which is the number of differentiating and also one lag order moving average. We specify a linear trend in data for any of the five trend specifications in Johansen (1995), namely, intercept and trend in CE-no trend in VAR. The VECM was introduced by Sargan (1964) and later popularized by Engle and Granger (1987); it is employed to correct disequilibrium and test for long- and short-run causality among cointegrated variables. The time series model that is proposed in this paper attempts to distinguish "expectations" from "information" in the price generating process. We assume that "a change in current price is dependent on changes in past changes in price, current and immediate-past information and expectations" but dependent on past residuals and random variables, such as cotton stockpile and cotton import. Thus, we define a VECM-lead model;

$\Delta \mathrm{P}_{\mathrm{t}}=\delta+\sum_{\mathrm{i}=1}^{\mathrm{P}} \alpha_{\mathrm{i}} \Delta \mathrm{P}_{\mathrm{t}-\mathrm{i}}+\sum_{\mathrm{i}=1}^{\mathrm{P}} \beta_{\mathrm{i}} \Delta \mathrm{S}_{\mathrm{t}-\mathrm{i}}+\sum_{\mathrm{i}=1}^{\mathrm{P}} \gamma_{\mathrm{i}} \Delta \mathrm{D}_{\mathrm{t}-\mathrm{i}}+\sum_{\mathrm{i}=1}^{\mathrm{P}} \theta_{\mathrm{i}} \Delta \mathrm{E}_{\mathrm{t}-\mathrm{i}}+\varepsilon_{\mathrm{t}}$

Where $\mathrm{P}_{t}, \mathrm{Stc}_{\mathrm{t}}$, and $\mathrm{I}_{\mathrm{t}}$ represent natural logarithms of nominal price, stockpile, and import, respectively; $\delta$ is the long-run risk premium; $\alpha_{\mathrm{i}} ; \beta_{\mathrm{i}}$ and $\gamma_{\mathrm{i}}$ are the coefficients; and $\mathrm{Ec}_{\mathrm{t}-\mathrm{j}}$ is the error correction term $(\mathrm{ECT})$, which is 
derived from the long-run cointegrating relationship, i.e., $P_{t}=\beta_{0}+\beta_{1}$ Stc $_{t}+\beta_{2} I_{t}+u_{t}$ and measures the magnitude of the past disequilibrium (it is referred to as the ECT because the deviation from long-run equilibrium is gradually corrected using a series of partial short-run adjustments). $\epsilon_{t}$ denotes the current abnormal disturbances and $\mathrm{Ec}_{\mathrm{t}-\mathrm{j}}$ is the lagged value of the residuals that are derived from the cointegrating regression of $\Delta \mathrm{P}_{\mathrm{t}}, \Delta$ Sct $_{\mathrm{t}}$, and $\Delta \mathrm{I}_{\mathrm{t}}$ (the differences in these variables), which capture their short-run disturbances. In the Eq. 4, the change in the endogenous variable is caused not only by their lags but also by the previous period's disequilibrium, i.e., $\mathrm{Ec}_{\mathrm{t}-\mathrm{j}}$. Given this specification, the presence of short- and longrun causality can be tested. Regarding Eq. (4), if the estimated coefficients on the lagged values of stockpile and import, i.e., the random variables, are statistically meaningful, increasing the stockpile and import have Granger causality into the changes in nominal prices in the short- or long-run.

We also perform the impulse response function within ten-step ahead forecasts in a VAR model environment to analyze the dynamic effect on all series of the system when the model receives an impulse or innovation. As we know structure VAR unrestricted and VEC embed economic theory within time series models, providing a convenient and powerful framework for policy analysis, with impulse response function (IRF) economic theory, can be employed to evaluate the impact of any variable on other variables in a dependent system (Jin-Lung Lin, 2006). With this analysis, we evaluate the degree of intensity of the shock (the effectiveness of a policy change) for all random variables of the system. For instance, when we bring one standard deviation into the system, we determine how much this shock or impulse would have affected the price and others variables in the system (the upward trend). We project the evaluation tenstep ahead forecast to estimate forecast error due to the impulse response, given that the residuals of cotton prices of past years and another time series will separately influence the determination of future cotton price index.

Thus, impulse response may be considered as follows:

Let $Y_{t}$ be a $k$-dimensional vector series that is generated by

$$
\begin{aligned}
& Y_{t}=A_{1} Y_{t-1}+\ldots+A_{p} Y_{t-p}+U_{t} \\
& \phi(B) U_{t}=\sum_{i=0}^{\infty} \phi_{i} U_{t-i} \\
& I=\left(I-A_{1} B-A_{2} B-\cdots-A_{p} B^{p}\right) \Phi
\end{aligned}
$$

Where $\operatorname{cov}\left(\mathrm{U}_{\mathrm{t}}\right)=\sum$, $\phi_{\mathrm{i}}$ represents the MA (moving average) coefficients that measure the impulse response. Specifically, $\phi_{\mathrm{jk}, \mathrm{i}}$ represents the response of variable $\mathrm{j}$ to a unit impulse in variable $\mathrm{k}$ that occurs in $\mathrm{i}$-th period. Because $\sum$ is usually non-diagonal, one variable cannot be shocked if other variables are fixed. Thus, some type of transformation is needed. We employ the Cholesky decomposition or factorization, which are the most popular matrix decompositions in linear algebra. If we let $\mathrm{P}$ be a lower triangular matrix such that $\Sigma=\mathrm{P} \mathrm{P}^{\prime}$, then eq. (5) can be rewritten as;

$$
Y_{t}=\sum_{i=0}^{\infty} \theta_{i} W_{t-i}
$$

Where $\Theta_{\mathrm{i}}=\Phi_{\mathrm{i}} \mathrm{P}, \mathrm{w}_{\mathrm{t}}=\mathrm{P}^{-1} \mathrm{U}_{\mathrm{t}}$, and $\mathrm{E}\left(\mathrm{w}_{\mathrm{t}} \mathrm{w}_{\mathrm{t}}^{\prime}\right)=\mathrm{I}$.

If we let $\mathrm{D}$ be a diagonal matrix with the same diagonals with $\mathrm{P}$ and $\mathrm{W}=\mathrm{P} \mathrm{D}^{-1}, \mathrm{~A}=\mathrm{DD}^{\prime}$. After some manipulations, we obtain;

$$
\mathrm{Y}_{\mathrm{t}}=\mathrm{B}_{0} \mathrm{Y}_{\mathrm{t}}+\mathrm{B}_{1} \mathrm{Y}_{\mathrm{t}-1}+\cdots+\mathrm{B}_{\mathrm{p}} \mathrm{Y}_{\mathrm{t}-\mathrm{p}}+\mathrm{V}_{\mathrm{t}}
$$

Where $\mathrm{B}_{0}=\mathrm{I}_{\mathrm{k}}-\mathrm{W}^{-1}, \mathrm{~W}=\mathrm{P} \mathrm{D}^{-1}, \mathrm{~B}_{\mathrm{i}}=\mathrm{W}^{-1} \mathrm{~A}_{\mathrm{i}} . \mathrm{B}_{0}$ is a lower triangular matrix with zero diagonals. The Cholesky decomposition imposes a recursive causal structure from the top variables to the bottom variables but not in the reverse order (Jin-Lung Lin, 2006).

\section{Dataset}

The dataset includes the yearly data of the nominal cotton prices index, cotton stock, and cotton import in the domestic market of the China from 1991 to 2014, which encompasses a period of 24 years. The data source is the USDA and NBS. In this paper, cotton stock and cotton import are expressed in terms of $1000480 \mathrm{Ib}$. Bales, and in case of cotton prices index is expressed in term of US dollar per ton. We depict the data presentation of the study to describe the behaviours and their evolving trends over time and their relevance from a statistical point of view, under the framework of the VEC environment, for subsequent use (At this stage of analysis, we could also endeavour to detect the similarities in real-valued prices index depicted in figure (1) previously with the subsequent figure (2) in nominal-valued prices index of cotton).

As shown in the figure (2), nonstationary values of log price, log stock, and log import cannot be disregarded. We assume that the evolving trend does not significantly differ among the variables, whereas the variances significantly differ. We have transformed the dataset of the time series into data logarithmic form for two reasons: first, to obtain normally distributed data; second, after statistical analysis, the obtained coefficients are considered as a percentage (\%) that expresses the elasticity of variation of random errors generated by the time series. Therefore, we construct the chart with two different patterns: first, the shape of the nominal-valued random variable, which is the logarithm term of $\log (\mathrm{P})$, $\log (\mathrm{STC})$, and $\log (\mathrm{I})$, presents the cotton prices index, stock, and import of cotton, respectively; second, the shape of the first difference, such as $\operatorname{DLog}(\mathrm{P})$, $\operatorname{DLog}(\mathrm{STC})$, and DLog(I). Our objective to obtain a Gaussian distribution in a time series has been achieved because the nonparametric skewness ( $\mathrm{x}$ ) and Kurtosis ( $\mathrm{x}$ ) of the random variable $\left(\mathrm{x}_{1}, \mathrm{x}_{2}\right.$, and $\left.\mathrm{x}_{3}\right)$ was smaller than the expected skewness of 0 and an expected excess kurtosis of 0 or 3 , relative to the nominal time series prior to their conversion in logarithmic terms. In addition, the Jarque Bera test of the goodness of fit our data were normally distributed and the null hypothesis of the skewness and the excess kurtosis were zero (which is the same as a kurtosis of 3), which indicate that the data are derived from a normal distribution. Therefore, we have determined that the values of JB asymptotically and of probability were 2.352 and 0.308 , respectively, which 
exceed the $\mathrm{p}$-value that is equivalent to a true $\alpha$ level $=$ 0.05 at given sample sizes (20) at approximately 0.1461 of the threshold. Our objective was to determine if the data are stationary; as we expected, this situation is only possible for the first difference I (1), as shown in figure (2) and in the figure in the annex (analysis of correlogram for the autocorrelation). The log of all series depicted in figure (2) appear similar but are not identical; they seem to share similar shocks or disturbances from policy decisions by policymakers in the agricultural sector in general and the industrial sector in particular of the production and marketing of cotton in China.
LOGP
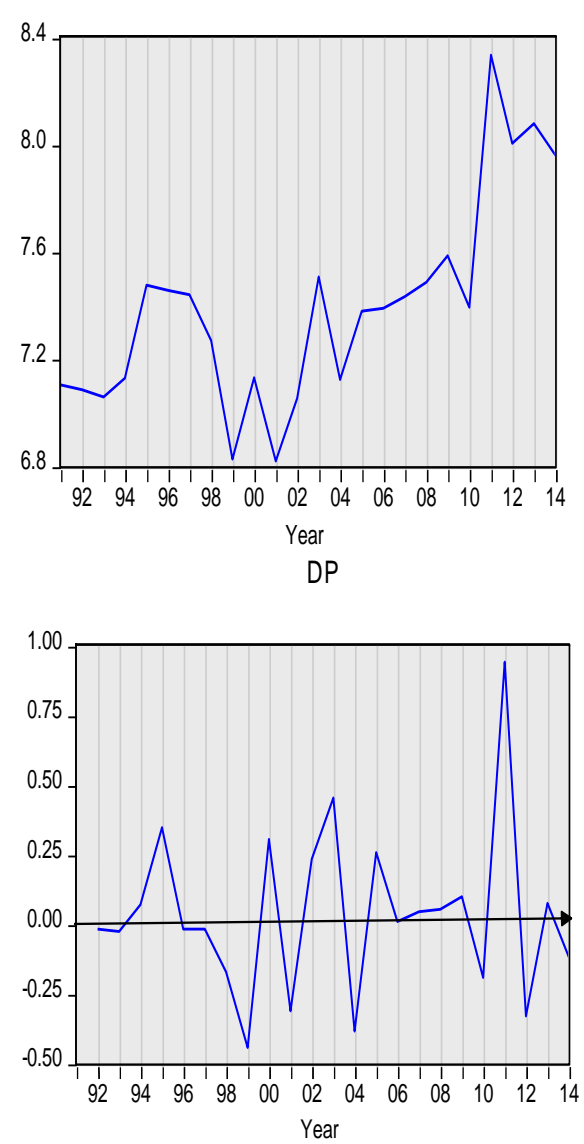

LOGSTC
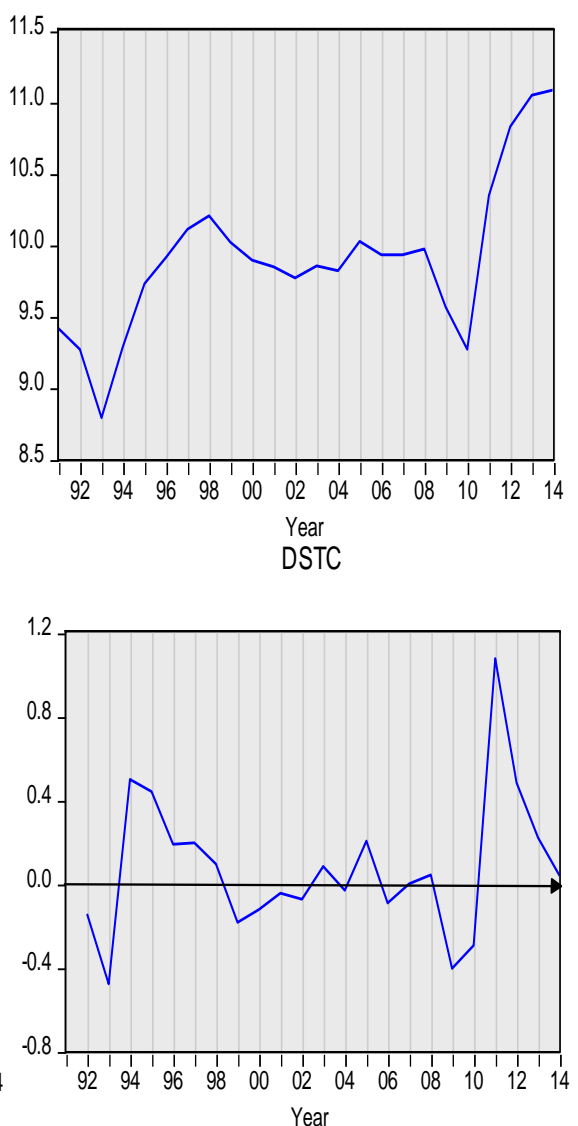

LOGI
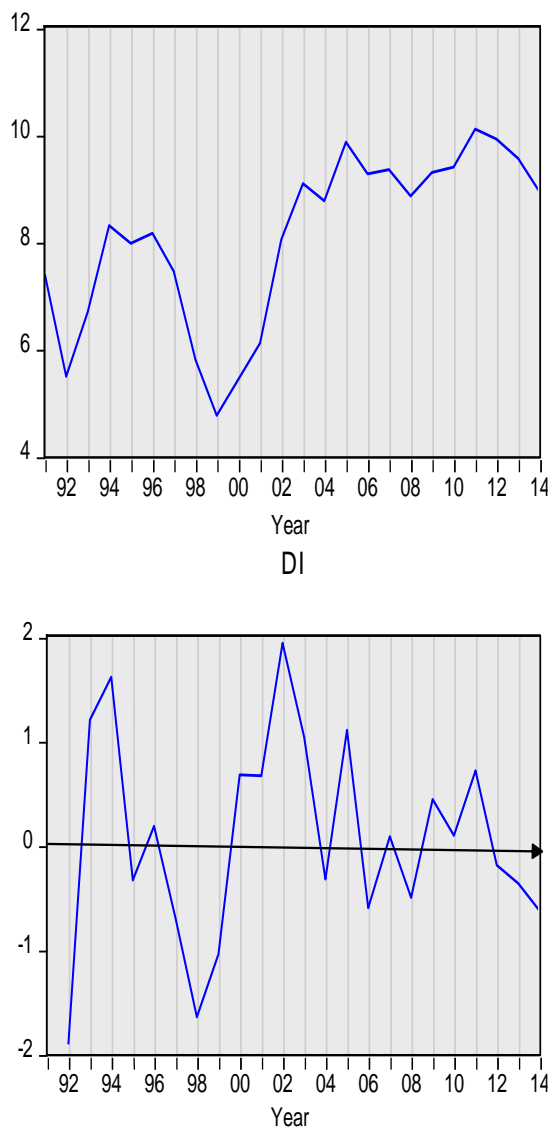

Figure 2 Nonstationary values of log price, log stock, and log

\section{Results and Interpretation}

As shown in the Table 1, virtually all data of the time series had become stationary at the first difference, whereas all series were nonstationary in the levels. To obtain these outcomes, the true data generating process (GDP) for each variable has been determined by following the procedures described in Enders, 1995 for the ADF test. The appropriate lag length was selected using Akaike's Information Criteria (AIC) and a maximum of 1 lag has been incorporated for two reasons; first, the yearly data; second, the limited sample size. We have included a constant and trend, such as the exogenous conditions, in the test equation. In the case for the PP test, we have also included a constant and trend in the test equation. Newey-West Bandwidth 2 employs the spectral estimated method of Bartlett Kernel. We are satisfied with the outcome of both analysis of the ADF and PP because each series was stationary in the first difference I (1) (refer to figure (2)). Thus, the null hypothesis that the series contains a unit root was discarded. However, we note that $\log (\mathrm{Stc})$ in the test of a unit root of Phillips Perron was stationary only at the threshold of $10 \%$ in the first difference. This situation has prevented us from continuing because we discovered that Log (Stc) was stationary in the first difference I (1) at a level of 5\% in the test of unit root of Augmented Dickey Fuller.

The lag length order selection of the equation model in this paper suggests a lag order of 1 . We have included a maximum lag length of 3 , which is the outcome in the equation of VAR, when SCI had selected lag 0 , whereas AIC, HQ, FPE, and LR had selected lag 1. Because the SIC tends to substantially underestimate the true lag order in small samples (Watson, M.W., 1994). Therefore, we prefer to use lag 1 throughout the treatment analysis of (VECMs) in this study, especially because this lag length is adopted by the majority of the entire selection criterion and the findings had satisfied our expectations concerning the lag length selected by AIC (Table 2).

To determine the rank from cointegrating the random variables, we employ the Johansen-Juselius approach, which is based on two statistic tests, namely, the trace test and the maximum eigenvalue. It begins by testing $\mathrm{H} 0: \mathrm{r}=$ 0 denotes that the series is not cointegrated by rejection of 
the null hypothesis; otherwise, it is cointegrated by accepting the null hypothesis, i.e., repeat for $\mathrm{HO}: \mathrm{r}=1$. In our case, both tests indicated 1 cointegrating eqn(s) at the 0.05 level $(22.03<25.87 ; 14.97<19.38)$. Since we have 1 eqn, which is more than zero and less than the number of variables (3), the series are cointegrating among the variables. Thus, we have two (2) rank orders that cointegrate in the cointegrated equation model that is employed in the VECM environment.

Referring to the economic theory of market approach, which states that prices vary or change as a function of balance of strength between supply and demand from different commodities in the market, we assume that the price of cotton is the dependent variable. However, cotton stockpile and cotton import are exogenous factors or factors that are exogenously determined as policy instruments to regulate cotton prices (upward or downward) in the market according to economic and policy goals. Because the Augmented Dickey-Fuller (ADF) and Phillips-Perron (PP) tests suggested no existence of a unit root in the dataset of random variables for which the data were integrated, i.e., stationary in short- or long-run equilibrium. This finding indicates that the data generating process (DGP) is likely to obtain relevant information, which may explain the behaviour of the evolving trend of prices and the policy changes in the sector industry of cotton in China (Table 3 ).

Table 1 Results of ADF and PP tests

\begin{tabular}{l|cccc}
\hline \multirow{2}{*}{ Variables } & \multicolumn{2}{c}{ Augmented Dickey-Fuller (ADF) } & \multicolumn{2}{c}{ Phillips-Perron (PP) } \\
\cline { 2 - 5 } & Levels & First differences & Levels & First differences \\
\hline Price & -2.935 & $-7.268^{* * *}$ & -2.947 & $-7.566^{* * *}$ \\
Stock & -2.602 & $-3.683 * * *$ & -1.680 & $-3.566^{* *}$ \\
Import & -1.891 & $-2.950^{* * *}$ & -2.339 & $-4.166^{* * *}$ \\
\hline
\end{tabular}

Notes: $* * *$ and $* *$ denote significance at $5 \%$ and $10 \%$, respectively, using the t-stat approach.

Table 2 Lag length order selection criteria

\begin{tabular}{l|ccccccc}
\hline Eq. Model & Lag & LogL & LR & FPE & AIC & SC & HQ \\
\hline & 0 & -26.96474 & NA & -0.004018 & -2.996474 & $-3.145834^{*}$ & -3.025631 \\
Eq. 1 & 1 & -15.43458 & $-18.44826^{*}$ & $-0.003171^{*}$ & $-2.743458^{*}$ & -3.340897 & $-2.860084^{*}$ \\
& 2 & -11.19214 & -5.515169 & -0.005507 & -3.219214 & -4.264733 & -3.423311 \\
& 3 & -3.770060 & -7.422082 & -0.007901 & -3.377006 & -4.870604 & -3.668572 \\
\hline
\end{tabular}

*Indicates lag order selected by the criterion, LR: sequential modified LR test statistic (each test at 5\% level), FPE: Final prediction error, AIC: Akaike information criterion, SC: Schwarz information criterion, HQ: Hannan-Quinn information criterion

Table 3 Unrestricted Cointegration

\begin{tabular}{ccccc|ccccc}
\hline \multicolumn{4}{c|}{ Rank Test of Trace } & \multicolumn{4}{c}{ Rank Test of Maximum Eigenvalue } \\
\hline HCE & EG & TS & CV & P** & HCE & EG & TS & CV & P** \\
None* & 0.762932 & 52.26482 & 42.91525 & 0.0045 & None* & 0.762932 & 30.22761 & 25.82321 & 0.0123 \\
At most 1 & 0.509848 & 22.03721 & 25.87211 & 0.1395 & At most 1 & 0.509848 & 14.97382 & 19.38704 & 0.1950 \\
At most 2 & 0.285628 & 7.063388 & 12.51798 & 0.3380 & At most 2 & 0.285628 & 7.063388 & 12.51798 & 0.3380 \\
\hline
\end{tabular}

HCE: Hypothesized No. Of CE(s), EG: Eigenvalue, TS: Trace Statistic, CV: 0.05 Critical value, Prob.**, Normalized cointegrating equation: Price $=$ $-2.431471-0.231760 \mathrm{Stc}-0.522350$ I with Log Likehood - 23.63779, * The rejection of the null hypothesis of no cointegrating equation at a $5 \%$ level of significance. The lag length was chosen using AIC, ** Mackinnon-Haug-Michelis (199) P-values

Table 4 Results of the error -correction model (ECM) Long-run

\begin{tabular}{c|lccccccccc}
\hline EM & \multicolumn{1}{c}{ EC } & C & SE & T & P & F & PR & R & AR & D-W \\
\hline & CointEq & -0.460 & 0.318 & 1.445 & 0.1676 & 5.620 & $0.004 *$ & 0.622 & 0.505 & 2.451 \\
Eq. 1 & Stc & 0.547 & 0.241 & 2.265 & 0.037 & - & - & - & - & - \\
& I & 0.061 & 0.066 & 0.925 & 0.368 & - & - & - & - & - \\
& C & 0.019 & 0.049 & 0.386 & 0.704 & - & - & - & - \\
\hline
\end{tabular}

EM: Eq. Model, EC: Error correction, C: Coefficient, SE: Std. Error, T: t-Statistic, P: Prob, F: F-statistic, PR: Prob (F-statistic), R: R-squared, AR: Adjusted R-squared, *Denotes significance at the $5 \%$ level, The optimal lag has been selected based on AIC. Godfrey LM tests have been applied; the results confirmed the absence of serial correlation in the ECM.

Considering the Johansen test, i.e., test of cointegrating of the residual values of the random variables, the results suggested some relationships among random variables of the system, which enable all series to move together in short- or long-run equilibrium. Then, the VEC model can be applied; thus, the ECM model is the test that confirms previous outcomes. We have established a null hypothesis that states that the coefficients can be interpreted as long run elasticity when the variables are in logarithms and one cointegrating vector is estimated. In our Eq. (refer to Table 4), we have not obtained the error term (ECM) in the dynamic system under consideration, which characterizes the deviation of the current state of cotton prices from its long-run relationship with other dependent variables. In our Eq. model (Eq.4), we discovered that the series was not significant $(16 \%)$ at level $5 \%$ of critical value (refer to Table 4). The cotton price, cotton stockpile, and cotton import are macroeconomic time series that are unrelated in the long-run equilibrium from a statistical point of view (shocks are not permanent). Although the results of the Johansen-Juselius test suggested the existence of one 
cointegrated equation, we suspect that the weakness of the sample size (with twenty four observations) undermined this lack of accuracy.

This model (Eq. model) is limited in the long run regarding explanations that we can derive from policy and social processes, which justifies the implication of policies that were established by the Chinese government for farmers to purchase cotton and to increase imports to increase the stockpile of the national reserve. Next, we check the ECMs to determine if the series estimated the spread of price- $\mathrm{P}_{\mathrm{t}^{-}}$to return to equilibrium in the short run after a change (innovation) to the cotton stockpiles $\left(\mathrm{STC}_{\mathrm{t}}\right)$ and cotton imports $\left(\mathrm{I}_{\mathrm{t}}\right)$ by the implementation of policies. However, the diagnostic test of the residuals, such as the correlogram of the residuals squared or the test of the goodness of fit of the model of Jarque-Bera had suggested that the data from the statistical series were normally distributed with a probability of approximately $57 \%$ and a risk of stumble of $5 \%$ (refer to the annex). The test of heteroskedasticity $(\mathrm{ARCH})$ or the Breuch-Godfrey serial correlation LM test were not significant with probabilities $98 \%$ and $5.7 \%$, respectively, which exceeds $5 \%$ of the threshold level, whereas the Durbin-Watson (D-W) statistic was robust and the information criterion (AIC,
SC, and HQ) was very small (refer to table 4). However, the results do not indicate whether the causal change from one unit to the regressors had the effect on the dependent variable of the system so that the series can return to equilibrium in the short run when it knew disequilibrium. We attempt to discover this unknown.

To verify the relationships between random variables in the system of ECM in an equilibrium in the short run, we employed the Wald Test and the Granger causality of short-run equilibrium when the series was stationary or cointegrated. The results suggest a short-term relationship that caused the random variable to move together step by step in an equilibrium economic, in the equation model of the ECM environment. Because the results of the test of Chi-square, as depicted in the table above, show that the probability was meaningful at a $5 \%$ level, i.e., the probability of $0.033 \%$ was less than the theoretical probability of 0.05 , the equilibrium in the system offset the disequilibrium from random shock in the short-term. If a $1 \%$ increase of the stockpiles or the imports is likely to increase the price index, the degree of the amplitude of this shock was evaluated using the test VECM Granger causality (Table 5 and 6)

Table 5 Results of Wald Test of Short-run equilibrium

\begin{tabular}{c|lccc}
\hline Eq. Model & \multicolumn{1}{c}{ Test Statistic } & Value & df & Probability \\
\hline \multirow{2}{*}{ Eq. (1) } & F-statistic & 3.4002 & 2 & $0.0588^{* *}$ \\
& Chi-square & 6.8004 & 2 & $0.033^{*}$ \\
\hline
\end{tabular}

With null hypothesis: Eq1. C(Stc) $=0, \mathrm{C}(\mathrm{I})=0, *$ and $* *$ Denotes significance at the $5 \%$ level and the $10 \%$ level, respectively, Restrictions in coefficients are linear.

Table 6 Results of VEC Granger Causality/Block Exogeneity Wald Tests

\begin{tabular}{|c|c|c|c|c|c|}
\hline Eq. Model & Dependent variables & Excluded & Chi-sq & $\mathrm{df}$ & Prob. \\
\hline \multirow{9}{*}{ Eq. (1) } & \multirow{3}{*}{ Price } & Stc & 5.133 & 1 & $0.023 *$ \\
\hline & & I & 0.856 & 1 & 0.354 \\
\hline & & All & 6.800 & 2 & $0.033 *$ \\
\hline & \multirow{3}{*}{ Stock } & $\mathrm{p}$ & 4.479 & 1 & $0.034 *$ \\
\hline & & I & 5.549 & 1 & $0.018 *$ \\
\hline & & All & 6.448 & 2 & $0.039 *$ \\
\hline & \multirow{3}{*}{ Import } & $\mathrm{p}$ & 0.496 & 1 & 0.481 \\
\hline & & Stc & 0.243 & 1 & 0.622 \\
\hline & & All & 0.587 & 2 & 0.745 \\
\hline
\end{tabular}

$*$ and $* *$ Denotes significance at the 5\% level and $10 \%$ level, respectively

Note that cointegration among the random variables in the system does not specify the direction of a cause and effect relationship between the variables. Economic theory ensures that Granger causality always exists in at least one direction (D. and L. Fisher, 1993). Therefore, we determine if the Granger causality direction among price (P), stocks (STC) and imports (I) exists. The estimation results for the VEC Granger causality between the time series under review are presented in the previous table. The analysis of the VEC Granger causality is based on the test of chi-square, and the probabilities are employed to measure elasticity causality, i.e., the magnitude of the shock among variables in the preset equation system. Here, our null hypothesis is that random variables in the ECM framework do not show causality among the variables in the system; otherwise, causality exists. The table provides the outcome of the Granger analyses of the test of VEC model Granger causality. If the probability values are statistically significant, then we can reject the null hypothesis; otherwise, we do not reject it. In this study, we deny the null hypothesis when the probability value exceeds $5 \%$ of the critical value; otherwise, we do not reject the null hypothesis when the probability value is less than $5 \%$ of the critical value. Between STC (stockpile) and P (price), a bidirectional "Granger cause" $(2.3 \%, 3.4 \%)$ is observed at the $5 \%$ significance level. This result indicates that a $1 \%$ increase of the stockpiles is likely to increase the price index by $46 \%$ and this estimate was significant; note that the shock is given from the side of cotton stocks. If the shock is given from the side of cotton prices $(\mathrm{P})$, the increase of stocks (STC) is the order of $54 \%$ and this estimate was significant and very similar. In practice, when both random variables ( $\mathrm{P}, \mathrm{STC})$ follow its mature counterparts in the short-run, a lead-lag 
relationship exists between them and the lead-lag (one) is on the order of $46 \%$ and $54 \%$ in one or another direction depending on the side from which the innovation is given. The value of lead-lag toward equilibrium in the short run is weak and rapidly decreases, i.e., $\phi<1$, $\phi \mathrm{T}$ tend to zero $(0)$ as $\mathrm{T}$ tend to infinity $(\infty)$; consequently, the shocks to the system are gradually eliminated. This situation is the hallmark of the model of the equation in our study: the lack of the long-run equilibrium because Eq. of ECM was not significant in long-run causality. In the case of the imports, the lead-lag in the short run was eliminated in the system, i.e., a causality relationship between the price and import of cotton does not exist, as shown in the table.

Impulse response to Cholesky (d.f. adjusted) One S.D. Innovations

As depicted in the Figure 3, the impulse response function of the decomposition method of Cholesky-dof adjusted shows that the impulse of the system equation that is performed in this study, if given one standard deviation innovation positive to price from price, is strongly positive in first period forecast but significantly decreases in the second period $(20 \%$ versus $0.12 \%$ in the second period). It becomes negative in the fourth period ($1.6 \%)$ forward or three years after the shocks and becomes positive in the sixth period with an unexpected percentage $(347 \%)$. In a subsequent period, it substantially decreases (at 1.4\%) in a level that is comparative to the level in the third period at the beginning $(2.8 \%)$; however, it remains positive. In the tenth period, it finishes weakly positive with only $1.5 \%$ percent, which indicates that cotton prices in China will experience a loss of more than 18.5 percent in nine years. I consider the benchmark (Cholesky measure of one standard deviation) as the first year (period) of the sample size (1991-2014). However, this Cholesky ordering is inconsistent with the literature and does not facilitate replicability. Therefore, this conclusion could be not true from a statistical point of view. Because the impulse response is a function of forecasts at increasingly distant horizons, misspecification errors are compounded with the forecast horizon. The difficult in computing appropriate standard errors for multiple step-ahead forecasts is that the impulse responses are restricted to exhibiting the eigenvalues with accuracy (refer to Jordà, Òscar and Kevin D. Salyer, 2004). Thus, Jordà, Òscar and Kevin D. Salyer (2004) propose an alternative model that is based on local projections for the improvement of the VARs to obtain a best estimate of mean square error (MSE) in estimating the forecast error, which is employed for estimation in the impulse response function, which we humbly assert that the framework exceeds the scope of our study. The results appear close to reality relative to the data generating process (DGP) and, thus, warrant attention. For instance, if we considered the impulse response of price to stock, prices remain negative throughout the system in ten periods of horizon forecasting. Thus, this issue appears interesting from an economic point of view due to the limited measures employed by policymakers to increase stock. It provides opportunities for new insight, to lessen the sole dependency of the sector industry of cotton in China on subsidies and enable other factors to adjust the fluctuations of cotton prices in the domestic market. Therefore, we have determined that the response of price to the shock of imports remains positive and in equilibrium if the impulse is given from imports toward price (refer to figure).
Response of LOGP to LOGP

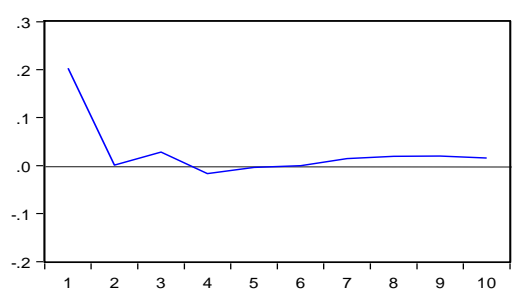

Response of LOGSTC to LOGP

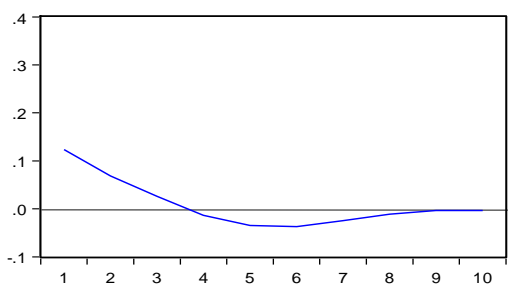

Response of LOGI to LOGP

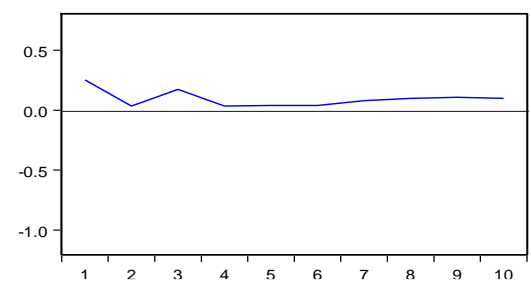

Response of LOGP to LOGSTC

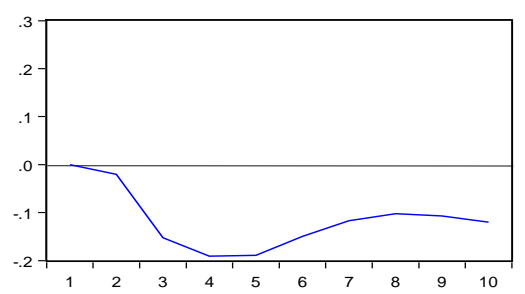

Response of LOGSTC to LOGSTC

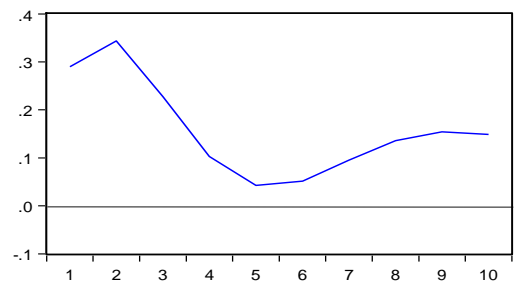

Response of LOGI to LOGSTC

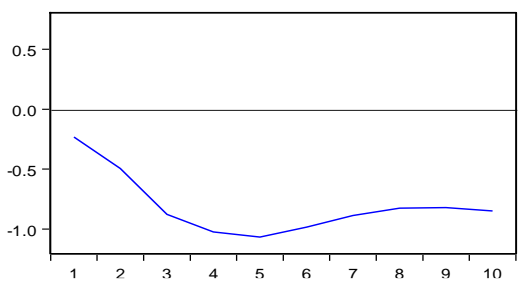

Figure 3 Response of price
Response of LOGP to LOGI

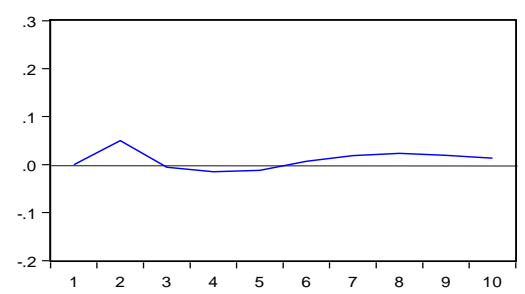

Response of LOGSTC to LOGI

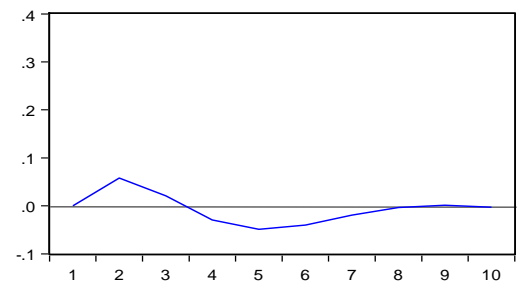

Response of LOGI to LOGI

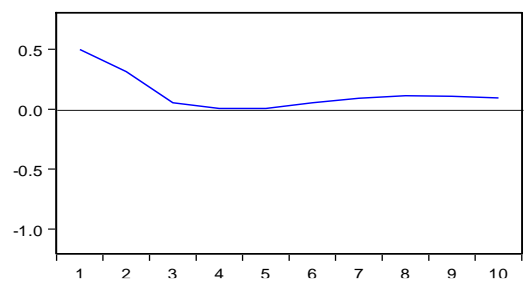




\section{Conclusion}

The objective of this study was to analyse the causality relationship between price and stocks and the importations of cotton in the Chinese domestic market and to explain the sources of volatilities of cotton prices in China via diverse mechanisms, such as macroeconomic and empirical techniques of the univariate analysis. Our estimation results indicate a bidirectional relationship between cotton prices and the stockpile of cotton, i.e., an increase in stockpiled cotton would increase the nominal value of the price of cotton in China. Our empirical findings support the notion that of a coupling of the stockpile strategy that was established by the Chinese government and the nominal value of the price of cotton in the Chinese domestic market. The rate of increase for the quantity of stockpile strategies has a direct one-to-one correlation with the upper value of the price of cotton in the domestic market in China. An increase in the quantity of cotton that is stockpiled in warehouses may cause a similar increase in the nominal value of the price of cotton in the Chinese domestic market. Concerning the relationship between the import and price of cotton, the empirical outcome suggests no causality in both directions for the two time series. During the study period, the stock of cotton increased approximately 4.3 times compared with the increase in 1991, which represents an increase of more than $432.4 \%$. Simultaneously, the prices increased by approximately 1.9 , which was an increase of more than $89.87 \%$ in two decades. The established measures for purchasing cotton by producers and other suppliers of the Chinese domestic market significantly contributed to an increase in the stock of cotton. This increase in the demand of the warehouse of the national reserve of the Chinese government has caused an increase in the cost of managing; the latter has increased the nominal value of the output of the cotton price. This finding implies that growth in stockpiles causes an increment in the nominal value of the cotton price due to an increase in cost management. Thus, an innovation (negative) to the demand for stockpile would unfavorably affect the high level of stock and subsequently diminish the level of nominal value of price. Because the relationship between the stockpile and the price index is reversible, policy makers have the opportunity to act to obtain the same consequence.

This study also applied the impulse response of the Cholesky test to examine the behavior of each random variable in the system given one standard deviation or a shock to the system and the response of these random variables to this impulse or to innovation. Our estimation results indicate that when one standard deviation or a shock was given from the prices, a suitable response to this impulse or this shock was not the price or stockpile national of the government but the import of cotton. Coupling exists between the cotton prices in China and the demand for cotton in countries beyond the domestic market in the China. The increased quantity of the demand of imported cotton may trigger a similar increase in the nominal value of price of cotton in the domestic market in China but not inversely. In the study period, imports of cotton increased by approximately 3.6 times compared with the imports in 1991, which represents an increase of more than $360.1 \%$. The established measures for the purchase of cotton by the Chinese government significantly contributed to an increasing in the stock of cotton via imports. This increased demand for the warehouse of the national reserve of the government Chinese has caused an increase in calls to importers; the latter has increased the nominal value of the value added $\operatorname{tax}$ (VAT) of the imports at the borders and the price of cotton. This finding implies that the need for increased support by the reserve national has caused an increase in the import of cotton and an increment in the nominal value of the cotton price via an increase in the nominal value of the value added tax (VAT). An innovation (negative) to demand imports would unfavorably affect the high level of stock and subsequently diminish the level of the nominal value of increased prices. Although a causality relationship between the increase of stocks and imports has not been statistically established.

To avoid adverse circumstances of trading in the domestic market of cotton in China, the Chinese government should enhance the understanding of managing stock of cotton from the national reserve and establish new approaches to supporting the well-being of cotton producers. These methods can be achieved via administrative consolidation, by applying the rules of uniformity to the selection of high-quality cotton, and via proper timing prior to the release of the first stocks. Adverse circumstances may be avoided by implementing new policies that promote innovation and the use of new technologies for a modern agriculture, which are independent of excessive subsidies. Despite a significant quantity of reserve of cotton, production has only increased approximately $14.9 \%$ compared with an increase in 1991. In most cases, lower production was attributed the disinterest of producers in the quality of their product because they knew that cotton would be purchased by the Chinese government. Conversely, the effective demand has remained low compared with the amount offered in the market, which is on the order of $54.2 \%$ (0.54 times) and $197.5 \%$ (1.97 times), respectively, when we consider 1991 as a benchmark due to the higher prices. Due to the concern for a lack of knowledge about the management of stocks, the coupling of the import growth and price growth of cotton may be achieved by reducing the restrictions on imports. China can reduce the pressure on the import tariff or fees of entrances, which will decrease prices. If China applies quotas to the imports with less restoration tariffs, a greater quantity of cotton will be imported, i.e., more competition and better cotton prices will be generated in the domestic market of China. This openness will encourage Chinese producers to enhance the quality of its outputs to withstand internal competition in the market in which they serve as landlords. To overcome the inflation of cotton prices, the massive subsidy policy via the purchasing of oversized tons of cotton, and the distrust of Chinese producers toward external competition, the Chinese government should promote the use of improved varieties in the central-southern and eastern part of China. To promote the development of the social life or welfare of peasants 
by giving them the means to adopt new technologies in agriculture by encouraging recycling and educational rigor in the modern techniques of agriculture to produce high-quality cotton, which will promote independent farmers.

\section{References}

Alexander C. 2001. Market models: A guide to financial data analysis. John Wiley \& Sons Ltd Impulse Response Analysis in Vector Autoregressions with Unknown Lag Order J. Forecast.20, 161-179

Dickey D, Fuller W. 1979. Distribution of the estimators for autoregressive time series with a Unit Root. J. the American Statistical Association, 74(366): 427-431

Diebold, F.X., Gunther, T. and Tay, A. 1998. Evaluating Density Forecasts with Application to Financial Risk Management, International Economic Review, 39, 863-883

Said, S, Dickey D. 1984. Testing for unit roots in autoregressive-moving average models of unknown order. Biometrika 71: 599-607

Jin-Lung Lin. 2006. Teaching Notes on Impulse Response Function and Structural VAR National Chengchi University May 2
Johansen, S, Juselius K. 1990. Maximum likelihood estimation and inference on cointegration with application to the demand for money. Oxford Bulletin of Economics and Statistics, 52(2): 169-210.

Johansen S. 1988. Statistical analysis of cointegrating vectors. Journal of Economic Dynamic and Control 231-254.

Jordà Ò, Salyer KD. 2004. Estimation and Inference of Impulse Responses by Local Projections, Review of Economic Dynamics, August

NBS. 1991-2014. National Bureau of Statistics, China's Statistical Year-book. Statistic Publishing House, Beijing

Phillips PC, Perron P. 1988. Testing for a unit root in time series regression. Biometrika, 75(2): 335-346.

Ralf P, David V. 2004. Agricultural Trade Policy Simulation Model (ATPSM), New York and Geneva, August

Stephen M, Fred G, James H. 2015. Cotton Policy in China, CWS-15c- 01 Economic Research Service/USDA, March

Tisdell CA. 1979. Economics of Fibre Markets. Pergamon Press, Oxford and New York.

USDA. 2014. Outlook Forum February 21, 2014 Washington, DC Shapiro, S.S (1980) How to test normality and other distributional assumptions. In: The ASQC basic references in quality control: statistical techniques 3, pp. 1-78. 